\title{
Effects of tungsten surface conditions on carbon deposition
}

Y. Ueda ${ }^{\mathrm{a} *}$, M. Fukumoto ${ }^{\mathrm{a}}$, A. Yamawaki ${ }^{\mathrm{a}}$, Y. Soga ${ }^{\mathrm{a}}$, Y. Ohtsuka ${ }^{\mathrm{a}}$, S. Brezinsek ${ }^{\mathrm{b}}$, T. Hirai $^{\mathrm{b}}$, A. Kirschner ${ }^{\mathrm{b}}$, A. Kreter $^{\mathrm{b}}$, A. Litnovsky ${ }^{\mathrm{b}}$, V. Philipps ${ }^{\mathrm{b}}$, A. Pospieszczyk ${ }^{\mathrm{b}}$, B. Schweer ${ }^{\mathrm{b}}$,

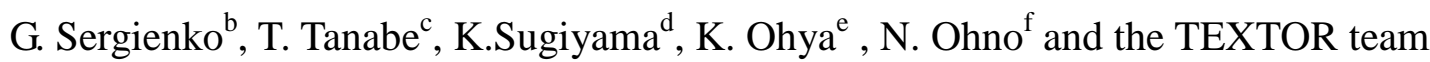
${ }^{\mathrm{a}}$ Graduate School of Engineering, Osaka University, Suita, Osaka 565-0871, Japan ${ }^{\mathrm{b} I n s t i t u t e ~ f u ̈ r ~ E n e r g i e f o r s c h u n g, ~ I F E: 4 ~ P l a s m a p h y s i k, ~ F o r s c h u n g s z e n t r u m ~ J u ̈ l i c h, ~ A s s o c i a t i o n ~}$ EURATOM-FZJ, Germany

' Interdisciplinary Graduate School of Engineering Science, Kyushu University, Fukuoka, Japan ${ }^{\mathrm{d}}$ Max-Planck-Institut für Plasmaphysik, EURATOM Association, D-85748 Garching, Germany ${ }^{\mathrm{e}}$ Institute of Technology and Science, The University of Tokushima, Tokushima, Japan ${ }^{\mathrm{f}}$ EcoTopia Science Institut, Nagoya University, Nagoya, Japan

\begin{abstract}
New results are shown on carbon deposition and mixed layer formation on tungsten surfaces in TEXTOR test limiter experiments by varying surface conditions such as surface roughness ( $R_{\mathrm{a}}: 10 \mathrm{~nm} \sim 1 \mu \mathrm{m}$ ), temperature $\left(300{ }^{\circ} \mathrm{C} \sim 900{ }^{\circ} \mathrm{C}\right.$ ), and initial surface carbon concentration ( $0 \% \sim 60 \%)$. It is found that surface roughness significantly affected C deposition for both W and graphite substrates such as increase in the $\mathrm{C}$ deposition and extension of the $\mathrm{C}$ deposition area. Not only the surface roughness parameter $R_{\mathrm{a}}$ but also detailed surface morphology closely relate to $\mathrm{C}$ deposition on tungsten. Carbon deposition hardly occurred at least above $\sim 520^{\circ} \mathrm{C}$ on tungsten under TEXTOR edge plasma conditions. Carbon behavior on tungsten at $770 \sim 930{ }^{\circ} \mathrm{C}$ depends on the incident carbon ion energy. Although tungsten and carbon mixing layers affected $\mathrm{C}$ deposition, their effect is less than the roughness effect.
\end{abstract}


PACS: 28.52.Fa (fusion reactor materials); 52.40.Hf (Plasma-material interactions)

JNM keywords: T1000 (Tungsten, Tungsten Alloys and Compounds); D0500(Diverter Materials); P0500 (Plasma-Material Interaction)

PSI-18 keywords: deuterium inventry, tritium, tungsten, carbon, redeposition

*Corresponding and presenting author address: 2-1 Yamadaoka, Suita, Osaka, 565-0871, Japan

*Corresponding and presenting author E-mail: yueda@eei.eng.osaka-u.ac.jp 


\section{Introduction}

In ITER, carbon materials are planned to be used at the strike point of divertor regions because of high thermal conductivity and non-melting feature. However, the use of carbon materials in the DT phase operation is still under serious discussion due to the problem of tritium retention mainly in redeposited carbon layers [1]. In addition, carbon deposition on diagnostic mirrors significantly reduces reflection of light, which must be avoided [2]. Therefore, it is important to improve the understanding of the mechanisms of carbon deposition on wall materials, especially on high Z materials, and to develop reliable models to evaluate the evolution of carbon deposition and its tritium retention.

Regarding carbon and tungsten mixing processes, there have been many basic experimental and theoretical studies, e.g. carbon implantation to tungsten and mixed layer formation [3-5], by the carbon ion beam with the ion energies in a keV range. The dynamic simulation code based on the Monte Carlo program TRYDYN [6] as well as EDDY [7] can successfully simulate experimental data including the effects of carbon diffusion in tungsten $[3,8]$. The simultaneous bombardment of carbon and hydrogen makes situation more complicated. Although dynamic simulation results including chemical sputtering agreed well with experimental data $[9,10]$, the detailed physical and chemical processes of chemical sputtering are unknown. In addition, depth distribution of carbon concentration in $\mathrm{W}$ and $\mathrm{C}$ mixed layers, especially near the top surface, was not simulated properly [11,12].

Considering actual surfaces of wall materials in fusion devices, the situation becomes much more complicated. We do not have enough results about the influence of surface pre-treatment (polishing and impurity doping) on carbon deposition. In addition, under edge plasma environment, various ions including hydrogen isotopes, helium, impurities from wall materials and edge cooling gas, can modify the surface morphology and surface atomic composition, and they can also have an influence on the process of carbon deposition and 
tritium retention. For example, helium ion irradiation modifies tungsten surfaces by forming He bubbles and nano-structures $[13,14]$. Therefore, more studies are necessary to understand basic processes of carbon and tungsten mixing, and the effects of surface pre-treatment and modification by plasma exposure on carbon deposition.

In this paper, new results are presented on carbon deposition and mixing on tungsten in TEXTOR test limiter experiments using the TEXTOR materials test facility [15]. In these experiments, surface conditions have been varied systematically, such as the surface roughness $\left(\mathrm{R}_{\mathrm{a}}: 10 \mathrm{~nm} \sim 1 \mu \mathrm{m}\right)$, temperature $\left(300{ }^{\circ} \mathrm{C} \sim 900{ }^{\circ} \mathrm{C}\right.$ ), and also the initial surface carbon concentration $(0 \% \sim 60 \%)$. These results are important for understanding carbon deposition and material mixing behavior on actual surfaces of tungsten plasma facing materials.

\section{Experimental}

The TEXTOR tokamak has a circular plasma cross section with a major radius of $1.75 \mathrm{~m}$ and a minor radius of $0.46 \mathrm{~m}$, which is defined by the toroidal belt limiter (ALT-II limiter). All the experiments shown in this paper were performed under TEXTOR standard Ohmic discharge conditions $\left(\mathrm{I}_{\mathrm{P}}=350 \mathrm{kA}, \mathrm{B}_{\mathrm{t}}=2.25 \mathrm{~T}, \mathrm{n}_{\mathrm{e}}=2.5 \times 10^{19} \mathrm{~m}^{-3}\right.$, D-plasma). Tungsten samples were installed on a graphite roof limiter inserted through the limiter lock system in the TEXTOR materials test facility [15]. The roof limiters were positioned with the nearest end 1-2 cm behind the LCFS (Last Closed Flux Surface) and extending deeper into the SOL (Scrape Off Layer). Several samples including a reference sample $\left(R_{\mathrm{a}} \sim 10 \mathrm{~nm}\right.$, pure W) were simultaneously exposed to the edge plasma to achieve identical exposure conditions.

Characterization of carbon deposition layers and mixed material layers was made by various surface diagnostics such as NRA (Nuclear Reaction Analysis) for the carbon and deuterium surface density, XPS (X-ray Photoelectron Spectroscopy) and SIMS (Secondary 
Ion Mass Spectrometer) for the depth profile of carbon concentration in the mixing layer combined with colorimetry for the thickness of carbon deposition layers. For NRA, the target was bombarded with $2.5 \mathrm{MeV}{ }^{3} \mathrm{He}$ ions to detect protons produced by $\mathrm{D}\left({ }^{3} \mathrm{He}, \mathrm{p}\right)^{4} \mathrm{He}$ and ${ }^{12} \mathrm{C}\left({ }^{3} \mathrm{He}, \mathrm{p}\right){ }^{14} \mathrm{~N}$ nuclear reactions [16]. Surface roughness was measured by a stylus-type surface profilometer (DEKTAK3) with $10 \mu \mathrm{m}$ in radius of curvature of the tip.

\section{Surface Roughness effects}

In TEXTOR, series of carbon deposition experiments by ${ }^{13} \mathrm{CH}_{4}$ tracer injection with test limiters have been carried out [17-19]. Deposition efficiency is lower for tungsten than graphite because of higher reflection of carbon ions and sputter enhancement of a few carbon layers on tungsten [18]. However, the surface roughness effect has been found to be at least as important for the erosion/deposition behavior as the substrate effect [20]. Two graphite limiters with different roughnesses $\left(R_{a} \sim 0.1 \mu \mathrm{m}\right.$ and $\left.R_{a} \sim 1 \mu \mathrm{m}\right)$ showed clear difference in

${ }^{13} \mathrm{C}$ deposition efficiency by a factor of $3-5$, which was larger than the difference in the deposition efficiency between carbon and tungsten substrate materials.

In this paper, we show the results of basic experiments to further validate the effect of roughness using a specially prepared roof limiter. Figure 1 shows a photo of the roof limiter after plasma exposure. On the ion drift side, 3 stripes of tungsten and 3 stripes of graphite (59 mm long and $10 \mathrm{~mm}$ wide) with different roughnesses were installed. The base temperature of the limiter was $\sim 300{ }^{\circ} \mathrm{C}$. The radial position of the roof limiter top was $\mathrm{r}=46$ $\mathrm{cm}$, same as LCFS. Electron temperature and density in the middle of discharge $(\mathrm{t}=2.0 \mathrm{~s})$ at $\mathrm{r}$ $=48 \mathrm{~cm}$ (roughly corresponds to the location of $\mathrm{C}$ deposition edges) were about $40 \mathrm{eV}$ and $2.5 \times 10^{18} \mathrm{~m}^{-3}$. These parameters were reproducible within the $\sim 10 \%$ error. The roof limiter was exposed to 37 shots of standard Ohmic plasma discharges.

In general, carbon deposition on test limiters was observed in a certain radial range 
as usually observed in TEXTOR. Net carbon deposition takes place when the gross deposition of carbon ions prevails the gross re-erosion of deposited carbon. In the lower part of the limiter representing locations deeper in the SOL, this condition is fulfilled because of a typically longer decay length of carbon impurity flux than that of eroding deuterium flux in the SOL, as well as lower electron temperature (lower ion bombardment energy) in the deeper SOL. Therefore, by comparing the radial lengthwise deposition profiles of the bar-shape samples, we can understand the difference in deposition characteristics. However, carbon deposition on the tungsten sample next to the graphite sample should be treated with care since sputtered carbon from the graphite sample enhancing the carbon deposition on the tungsten sample. This effect was observed on the tungsten sample with the roughness of 22 nm, see Fig. 1, since the enhanced deposition was observed only near the edge adjacent to the carbon sample. In addition, another enhanced deposition was found near the other edge on the same tungsten sample. This is due to the presence of a step between the two adjacent tungsten samples: the surface of the sample with a roughness of $R_{\mathrm{a}} \sim 180 \mathrm{~nm}$ was slightly protruding over that with $R_{\mathrm{a}} \sim 22 \mathrm{~nm}$.

The experiment shows clearly that roughness affects the carbon deposition characteristics on both tungsten and graphite. Figure 2 shows the carbon and deuterium deposition profiles along the center line of the tungsten bar-shape samples (Fig. 2 (a) and (b)) and deuterium deposition on the graphite samples (Fig. 2(c)) measured by NRA. Carbon deposition was very low $\left(\sim 0.03 \times 10^{18} \mathrm{~cm}^{-2}\right)$ in the erosion area of tungsten (up to about a minor radius of $r=48 \mathrm{~cm}$ for $\mathrm{R}_{\mathrm{a}} \sim 9 \mathrm{~nm}$ ) and increased rapidly over a certain radial position towards the deposition area, see Fig. 1(a). This sharp boundary between erosion and carbon deposition can be reproduced by the simulation using EDDY code [21]. Once carbon starts to deposit on tungsten, subsequent deposition takes place on a new carbon surface, which accelerates deposition speed, eventually to form the sharp boundary. As the surface roughness 
increased, the boundaries moved towards the erosion area. For the roughest case $\left(\mathrm{R}_{\mathrm{a}} \sim 180\right.$ $\mathrm{nm})$, the carbon deposition profile has a long tail toward the top of the limiter. These results suggest that a certain level of roughness significantly increases the deposition area. The profiles of D retention followed very closely those of the carbon profiles (Fig. 2(b)). For the roughest case ( $\left.R_{\mathrm{a}} \sim 180 \mathrm{~nm}\right)$, the D retention profile has a long tail toward the erosion area, similar to the $\mathrm{C}$ profile. The ratio of $\mathrm{D} / \mathrm{C}$ is $0.1-0.15$ in the carbon deposition area, which roughly corresponds to the published data [22].

With regard to the carbon deposition on graphite, only D profiles are shown in Fig. 2(c) since distinguishing deposited carbon from substrate carbon is difficult for all graphite samples. It was found that D retention on graphite was enhanced by surface roughness. From the colorimetry, the thickness of the deposition layer on the graphite $\left(R_{\mathrm{a}} \sim 70 \mathrm{~nm}\right)$ was $\sim 1.3$ times that on the tungsten $\left(R_{\mathrm{a}} \sim 180 \mathrm{~nm}\right)$. On the other hand, the ratio of $\mathrm{D}$ retention on the graphite to the tungsten was $\sim 1.8$. Since it is reasonable to assume $\mathrm{D} / \mathrm{C}$ ratio in the $\mathrm{C}$ deposition layers was almost similar for graphite and tungsten, some of D retention on the graphite could be in the graphite substrate. But a dominant part of $\mathrm{D}$ retention was still in the C deposition layers and the $\mathrm{D}$ retention was roughly related to the amount of $\mathrm{C}$ deposition. Thus, as can be seen in Fig. 2(c), the $\mathrm{C}$ deposition was also enhanced with surface roughness for graphite. In this case, however, no sharp boundary between deposition and erosion was observed in contrast to tungsten. This is because the deposition layer material and the substrate material were the same.

In the experiments described above, we changed the roughness by changing polishing processes. A similar experiment was performed with "plasma-roughened" surface by He plasma exposure to the tungsten stripe beforehand, see Fig. 3(a) (sample (5)). This sample was pre-exposed at $1300{ }^{\circ} \mathrm{C}$ to a high density He plasma in NAGDIS-II [23]. After the He exposure, tungsten nano-structure was formed [14]. The loosely bound nano-structure 
were mechanically removed from the surface before exposure in TEXTOR. The surface morphology is shown in Fig. 3(b). Even after this treatment, some nano-structure still remained. The surface roughness of this sample after the TEXTOR plasma exposure was only $\sim 15 \mathrm{~nm}$. The nano-structure could be too fine for the stylus-type profilometer to detect. Carbon deposition profiles on this sample together with the $\mathrm{H}$ and $\mathrm{C}$ ion pre-irradiated $\mathrm{W}$ samples (detailed explanation in section 5) are shown in Fig. 3(c) after exposure to 43 shots of TEXTOR discharges at $r=46 \mathrm{~cm}$. Carbon deposition was clearly enhanced on this He-roughened tungsten, compared with the other tungsten samples. This $\mathrm{C}$ deposition profile also showed a tail towards the erosion area, similar to the roughest tungsten sample $\left(R_{\mathrm{a}} \sim 180\right.$ $\mathrm{nm}$ ), see Fig. 2. The deuterium retention with the $\mathrm{D} / \mathrm{C}$ ratio of $\sim 0.1$ was observed only in the carbon deposition layer.

The mechanism of carbon deposition enhancement by surface roughness could be prompt redepostion of sputtered or reflected particles on the local wrinkles [20]. This phenomenon reduces effective sputtering yield and reflection coefficient, which turns the particle balance between deposition and erosion into favor of deposition. So far, works have been done to study the effect of surface roughness on sputtering [24-26], but its effect on deposition and $\mathrm{T}$ retention has not been properly modeled. Therefore, to evaluate the total amount of carbon deposition and T retention in the deposition layer, the effects of surface roughness should be included.

\section{Carbon deposition at elevated temperatures}

The carbon deposition on tungsten was studied as a function of temperature by using a specially prepared partially heatable limiter, in which a small BN heater was embedded beneath the tungsten sample on the left side, see Fig. 4. Two exposure experiments (EXP-A for Fig. 4(a) and EXP-B for Fig. 4(b)) were made with the different initial temperature of the 
heated sample $\left(520^{\circ} \mathrm{C}\right.$ for EXP-A and $770{ }^{\circ} \mathrm{C}$ for EXP-B). The initial temperature of the non-heated sample was the same as that of the roof limiter itself $\left(240{ }^{\circ} \mathrm{C}\right.$ for EXP-A and $280{ }^{\circ} \mathrm{C}$ for EXP-B). The limiter was set $1.5 \mathrm{~cm}$ behind LCFS ( $\mathrm{r}=47.5 \mathrm{~cm}$, limiter top) and exposed to 18 shots (EXP-A) and 23 shots (EXP-B). The temperature of the heated sample was measured by an embedded thermocouple, while the temperature of the non-heated sample was measured by a pyrometer, which was calibrated by the thermocouple in the limiter in thermal equilibrium. The thermocouple inside of the heated sample was fixed with graphite bond, from which as the temperature was raised above about $700{ }^{\circ} \mathrm{C}$, carbon oxide (CO) was desorbed and leaked out from the gap between the heated and non-heated samples, see Fig. 4(c). This "gas puff" occurred by chance but was very useful to compare the deposition characteristics between the two samples.

From Fig. 4(a) and 4(b), carbon deposition was visually observed on the non-heated samples (right), while no deposition was observed on the heated samples (left). The carbon deposition by the CO gas puff was also observed only on the non-heated sample, see Fig. 4(b) in the circle marked by A. According to NRA measurements, only the carbon deposition layer on the non-heated samples contained measurable deuterium with a D/C ratio of $\sim 0.35$ (EXP-A) and 0.25 (EXP-B). The difference in D/C ratio could be due to the difference in temperature $\left(240 \rightarrow 280^{\circ} \mathrm{C}\right.$ for EXP-A, $280 \rightarrow 340{ }^{\circ} \mathrm{C}$ for EXP-B).

The reason for the absence of carbon deposition on the heated tungsten (520 $\rightarrow$ $600{ }^{\circ} \mathrm{C}$ ) for EXP-A could be the higher re-erosion yield of deposited carbon by chemical sputtering. The importance of chemical sputtering on the erosion of carbon and tungsten mixed layers was pointed out by Schmid et al. [10]. Their model includes a chemical sputtering effect which successfully explained the change of carbon deposition/tungsten erosion irradiated by $\mathrm{CH}_{3}{ }^{+}$at $500{ }^{\circ} \mathrm{C}$. However, the detailed mechanism of the chemical sputtering of the mixed layer has not been well understood. One of the key results was shown 
in ref. [27], in which surface carbon concentration and its chemical state depending on temperature were shown for the carbon and tungsten mixed layers produced by $1 \mathrm{keV} \mathrm{H}$ and C mixed ion beam irradiation to tungsten. This showed tungsten carbide layers did not change with temperature, while graphitic carbon layer disappeared near the peak temperature of chemical sputtering (913 K).

In order to observe the carbon behavior in more detail, 2D profiles of the $\mathrm{C}$ areal density for EXP-B was measured by NRA, see Fig. 5. In area B of the heated sample, some carbon was observed, though no carbon deposition was found on the surface. Since the temperature of this sample was high enough for carbon atoms to diffuse in tungsten [3], diffusion mixing of carbon and tungsten could take place. The depth profile of carbon in the heated sample measured by SIMS is shown in Fig. 6. The measurement positions are indicated in Fig. 5 (SIMS 1 and SIMS 2). At the position of SIMS 2, carbon atoms diffused into the tungsten up to about $45 \mathrm{~nm}$ in depth (sputter rate is about $1.5 \mathrm{~nm} / \mathrm{s}$ ), while almost no diffusion of carbon atoms into the bulk was observed at the position of SIMS 1. The absolute carbon concentration near the surface (SIMS 2) was about 30\% by the XPS measurement. According to the results on concentration dependent diffusion of carbon in tungsten [3], the diffusion coefficient $D$ of carbon in tungsten at $1030 \mathrm{~K}$ (close to our experimental condition, $1043 \mathrm{~K}\left(770{ }^{\circ} \mathrm{C}\right)$ ) is $4 \times 10^{-20} \mathrm{~m}^{2} \mathrm{~s}^{-1}$. The relation $\Delta x=2 \sqrt{D t}$ and $\mathrm{t}=8,400$ s (total sample heating time) yields a diffusion length $\Delta x$ of $\sim 37 \mathrm{~nm}$, which roughly agrees with the experimental carbon diffusion length ( $\sim 4 \mathrm{~nm})$.

As was shown in Fig. 4(b), carbon deposition due to CO gas puff was not observed on the heated sample. According to the 2D NRA measurement in Fig. 5, carbon did not exist inside of the heated sample either. Therefore, all of the deposited carbon ions were re-eroded in this case. In area B, however, some of the implanted carbon ions diffused deeper into the bulk of tungsten. In both areas $\mathrm{A}$ and $\mathrm{B}$, if the temperature was low (e.g. $\sim 300^{\circ} \mathrm{C}$ ), carbon 
deposition could occur. The difference of carbon behavior between area A and area B can be attributed to the carbon bombardment energy. Since implanted carbon ions in area B are multi-charged (mostly $\mathrm{C}^{4+}$ ), their energy can approach about $500 \mathrm{eV}$ or higher (e.g. if $T_{\mathrm{e}}=T_{\mathrm{i}}$ $=40 \mathrm{eV}$, energy $\sim 4 \times 3 T_{\mathrm{e}}+2 T_{\mathrm{i}} \sim 580 \mathrm{eV}$ ). On the other hand, most of carbon ions originated from $\mathrm{CO}$ gas are singly charged $\left(\mathrm{C}^{+}\right.$or $\left.\mathrm{CO}^{+}\right)$and far from thermalization with background plasma. Therefore, their energy is much lower (e.g. if $T_{\mathrm{e}}=40 \mathrm{eV}$ and $T_{\mathrm{i}}=0 \mathrm{eV}$, energy $\sim 120$ $\mathrm{eV}$ ). According to TRIM code, the ion range of $120 \mathrm{eV}$ carbon ions in tungsten (normal incidence) is just $1 \mathrm{~nm}$, corresponding to a few ML. One of the possible mechanisms of enhanced erosion of these carbon atoms is surface segregation followed by sputtering enhanced by reflected D ions, or simple sublimation. Radiation enhanced sublimation may also occur at this temperature $\left(\max 930^{\circ} \mathrm{C}\right)[10]$.

\section{Effects of pre-irradiation of carbon ions}

Under steady state erosion conditions of tungsten by D and C mixed ion irradiation, certain carbon depth profile is maintained. If this $\mathrm{C}$ profile is disturbed by some reasons, for example, increase in carbon concentration in plasma or increase in ion energy, particle balance between erosion and deposition can change. In some cases, the initial particle balance does not recover even after the disturbance disappear due to the change of atomic composition of substrates.

To simulate this situation, carbon and hydrogen ion beam was used to pre-irradiate tungsten to form $\mathrm{C}$ and $\mathrm{W}$ mixed layers, then these samples were exposed to TEXTOR edge plasmas. Pre-irradiation was made by $1 \mathrm{keV} \mathrm{H}$ beam with a small amount of carbon $(\sim 0.1 \%$, $\sim 0.3 \%$, and $\sim 0.9 \%$ ) by the high-flux ion beam device [28]. Carbon concentration near the surface measured by XPS was $\sim 60 \%, \sim 40 \%$, and $\sim 10 \%$, respectively. The difference in carbon deposition between three pre-irradiated samples was clear. As carbon concentration near the 
surface was increased, C deposition was enhanced. On the other hand, no deposition took place on the reference $\mathrm{W}$ sample without pre-irradiation. It is noted that only $10 \%$ of carbon concentration near the surface enhanced C deposition. These profiles, however, did not have tails, different from the case for the He pre-exposed sample. Therefore, surface roughness affected C deposition more significantly than the presence of $\mathrm{W}$ and $\mathrm{C}$ mixed layers.

\section{Conclusion}

Carbon deposition on tungsten was studied in TEXTOR test limiter experiments with various surface conditions. It was found that surface roughness significantly affected C deposition for both $\mathrm{W}$ and graphite substrates such as increase in the $\mathrm{C}$ deposition layers and extension of the $\mathrm{C}$ deposition area. This effect was more pronounced for the tungsten sample with $R_{\mathrm{a}} \sim 180 \mathrm{~nm}$ (engineering surface) and He pre-exposed W surface with the complicated surface rough structure with only $R_{\mathrm{a}} \sim 15 \mathrm{~nm}$. From these data, not only surface roughness parameter $R_{\mathrm{a}}$ but also detailed surface morphology need to be considered for $\mathrm{C}$ deposition on tungsten.

In terms of $\mathrm{C}$ deposition on tungsten at elevated temperatures, $\mathrm{C}$ deposition hardly occurred at least above $\sim 520{ }^{\circ} \mathrm{C}$ under the TEXTOR edge plasma conditions. Carbon behavior on tungsten at $770 \sim 930{ }^{\circ} \mathrm{C}$ depends on the incident carbon ion energy. Therefore, more sophisticated modeling is needed for C and W material mixing.

Increase in $\mathrm{C}$ deposition with the surface $\mathrm{C}$ concentration in tungsten (up to 60\%C) was observed. Only $10 \%$ of C in tungsten enhanced C deposition, but its effect was less pronounced than the surface roughness effect. 


\section{References}

[1] J. Roth, E. Tsitrone and A. Loarte, Nucl. Instrum. Methods B258 (2007) 253.

[2] A. Litnovsky et al., J. Nucl. Mater. 363-365 (2007) 1395.

[3] K. Schmid and J. Roth, J. Nucl. Mater. 302 (2002) 96.

[4] W. Eckstein, V. Shulga and J. Roth, Nucl. Instrum. Methods Phys. Res. B153 (1999) 415.

[5] R. Kawakami and K. Ohya, Jpn. J. Appl. Phys. 42 (2003) 5266.

[6] W. Möller, W. Eckstein and J. Biersack, Comput. Phys. Commun. 51 (1988) 355.

[7] K. Ohya, J. Kawata and A. Harada, Rad Eff. Def. Sol. 142 (1997) 401.

[8] K. Schmid, J. Roth and W. Eckstein, J. Nucl. Mater. 290-293 (2001) 148.

[9] K. Krieger and J. Roth, J. Nucl. Mater. 290-293 (2001) 107.

[10] K. Schmid and J. Roth, J. Nucl. Mater. 313-316 (2003) 302.

[11] T. Shimada et al., J. Nucl. Mater. 329-333 (2004) 747.

[12] R. Kawakami et al., Jpn. J. Appl. Phys. 42 (2003) 7529.

[13] D. Nishijima et al., J. Nucl. Mater. 313-316 (2003) 97.

[14] M. Baldwin and R. Doerner, Nucl. Fusion 48 (2008) 035001.

[15] B. Schweer et al., Fusion Sci. Technol. 47 (2005)

[16] V. Alimov et al., J. Nucl. Mater. 282 (2000) 125.

[17] P. Wienhold et al., J. Nucl. Mater. 290-293 (2001) 362.

[18] A. Kreter et al., Plasma Phys. Control. Fusion 48 (2006) 1401.

[19] A. Kreter et al., J. Nucl. Mater. 363-365 (2007) 179.

[20] A. Kreter et al., submitted to Plasma Phys. Contr. Fusion 000 (2008) 000.

[21] K. Ohya et al., J. Nucl. Mater. 337-339 (2005) 882.

[22] V. Alimov, Physica Scripta T108 (2004) 46.

[23] N. Ohno et al., Nucl. Fusion 41 (2001) 1055.

[24] M. Künster et al., Nucl. Instrum. Methods B145 (1998) 320. 
[25] J. Brooks and D. Ruzic, J. Nucl. Mater. 176-177 (1990) 278.

[26] D. Ruzic, Nucl. Instrum. and Meth. 47 (1990) 118.

[27] Y. Ueda et al., Fusion Eng. Des. 81 (2006) 233.

[28] Y. Ueda et al., Fusion Eng. Des. 61-62 (2002) 255. 


\section{Figure Captions}

Fig. 1 Photograph of the roof limiter in TEXTOR experiments. Three W samples with the roughness $R_{\mathrm{a}}$ of $\sim 9 \mathrm{~nm}, \sim 22 \mathrm{~nm}$, and $\sim 180 \mathrm{~nm}$ and three graphite samples with $R_{\mathrm{a}} \sim 70 \mathrm{~nm}$, $\sim 350 \mathrm{~nm}$, and $\sim 700 \mathrm{~nm}$ were installed.

Fig. 2 Line profiles of (a) C areal density on W, (b) D areal density on tungsten, and (c) D areal density on graphite, measured by NRA along the center line of each bar-shape sample.

Fig. 3 Photograph of the roof limiter for pre-treated W samples (a); (1) W with $1 \mathrm{keV}(\mathrm{H}+$ $0.1 \% \mathrm{C})$ pre-irradiated, (2) W with $1 \mathrm{keV}(\mathrm{H}+0.3 \% \mathrm{C})$ pre-irradiated, (3) W with $1 \mathrm{keV}(\mathrm{H}+$ 0.9\%C) pre-irradiated, (4) W without pre-treatment, (5) W with He plasma pre-exposure at $1300{ }^{\circ} \mathrm{C}$. Surface morphology of He pre-exposed tungsten before TEXTOR plasma exposure is shown in (b). Carbon areal density profiles is shown in (c).

Fig. 4 Photograph of the partially heated limiter after TEXTOR plasma exposure : (a) low temperature experiment (EXP-A) and (b) high temperature experiment (EXP-B). The inside structure of the heated sample is shown in (c).

Fig. 5 2D profile of C areal density measured by NRA for EXP-B. "SIMS 1" and "SIMS 2" indicate measurement positions of SIMS.

Fig. 6 Carbon and tungsten depth profiles at the positions of (a) SIMS 1 and (b) SIMS 2 (shown in Fig. 5) measured by SIMS. Sputter speed is roughly $1.5 \mathrm{~nm} / \mathrm{s}$. 


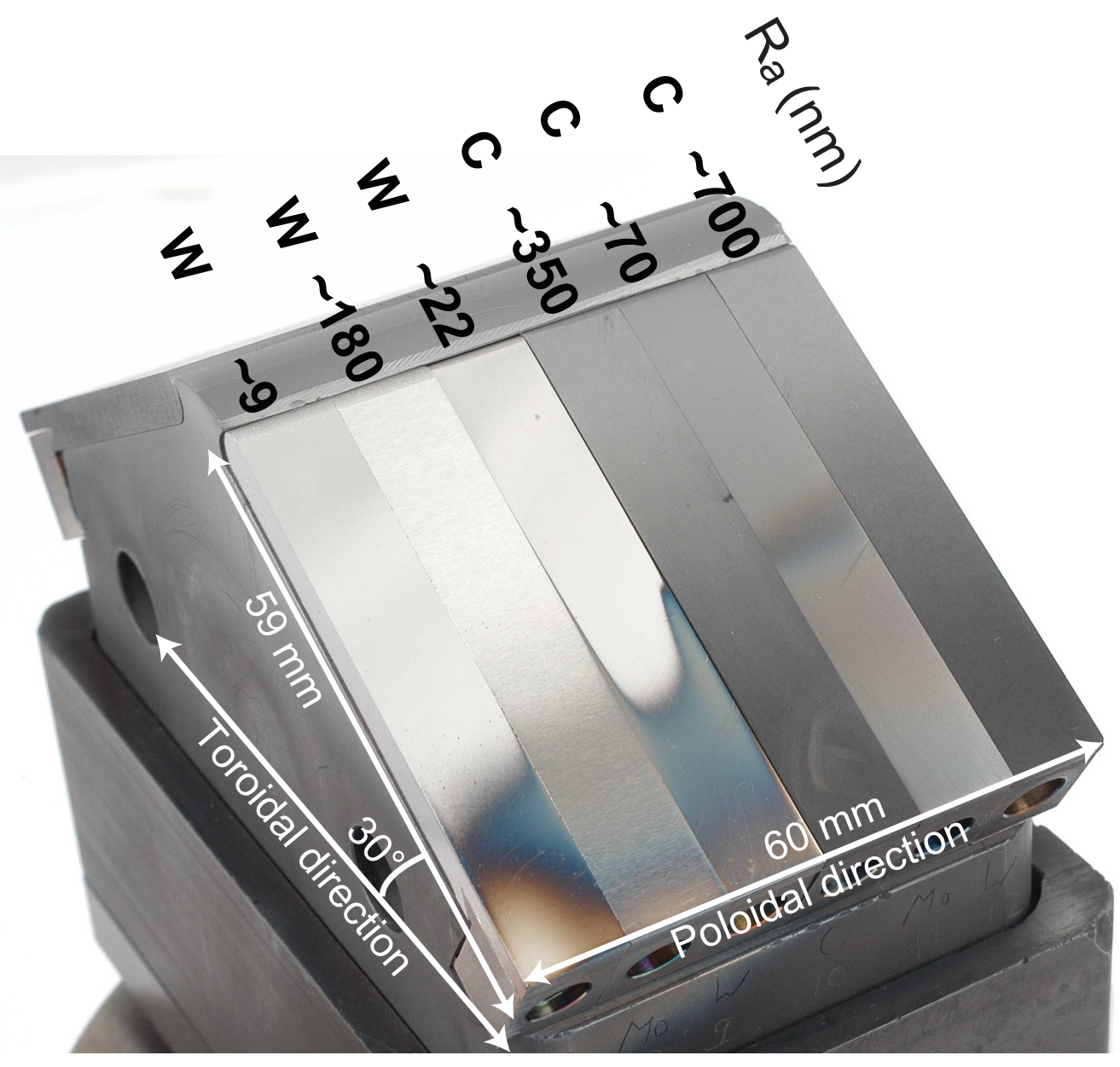

Fig. 1 

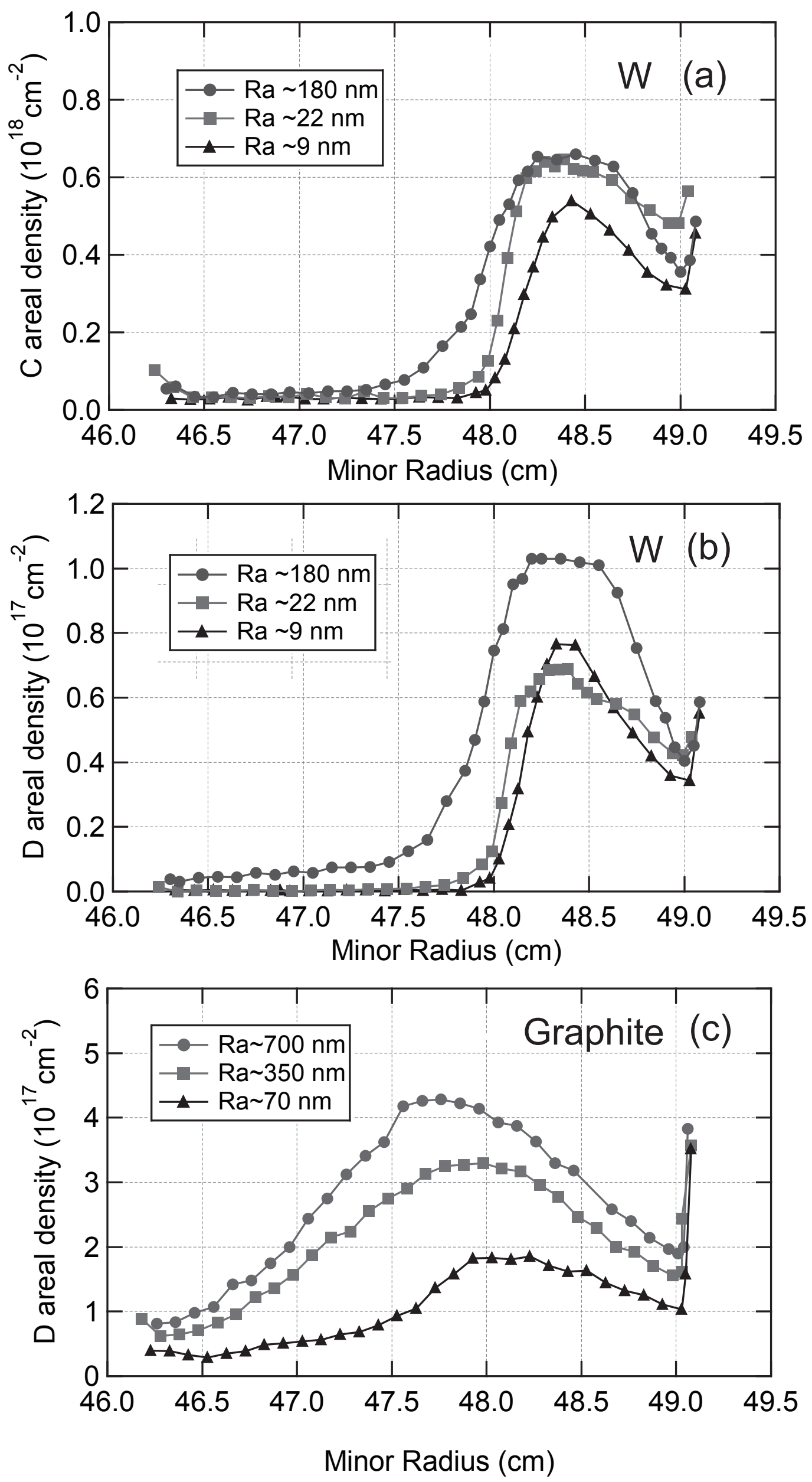

Fig. 2 

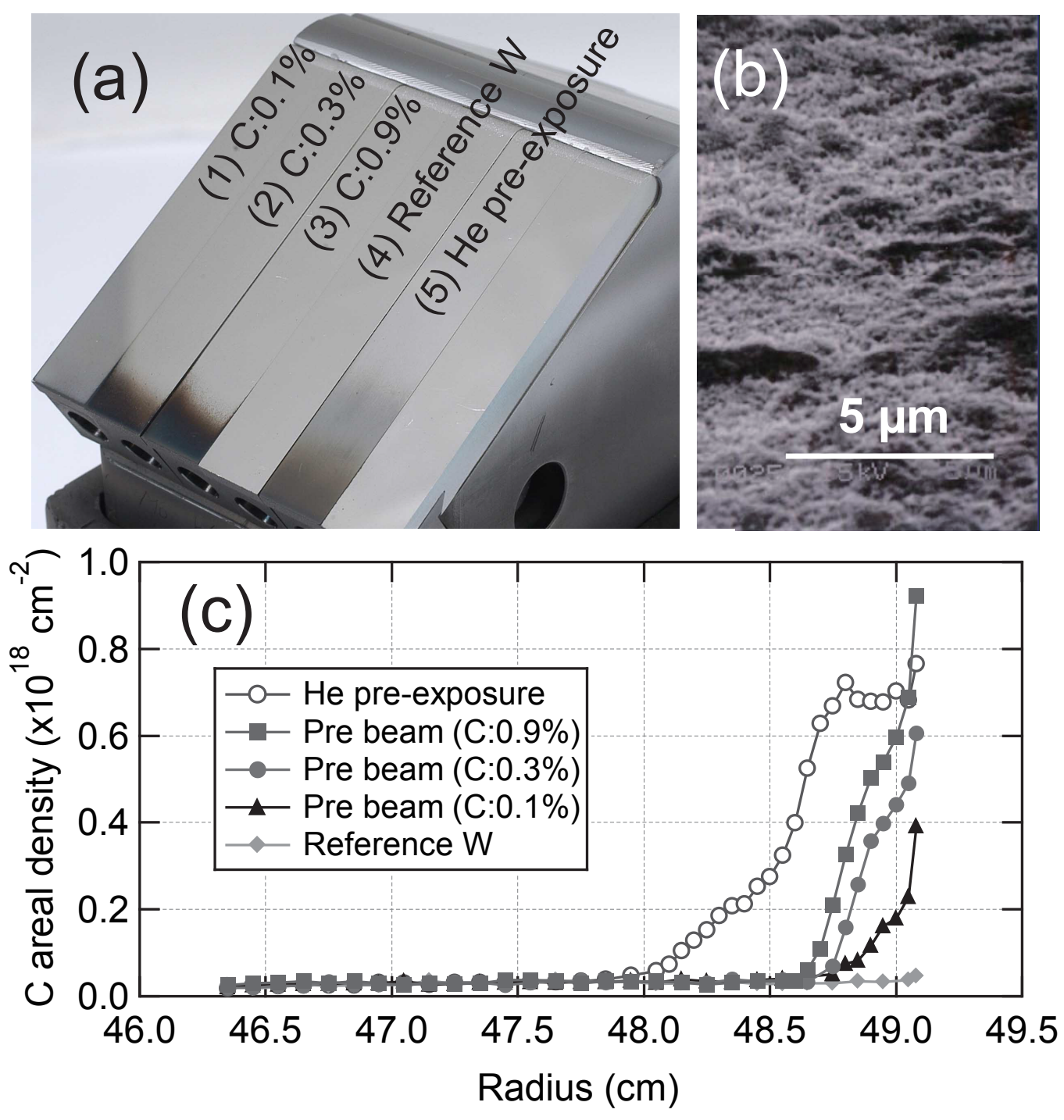

Fig. 3 

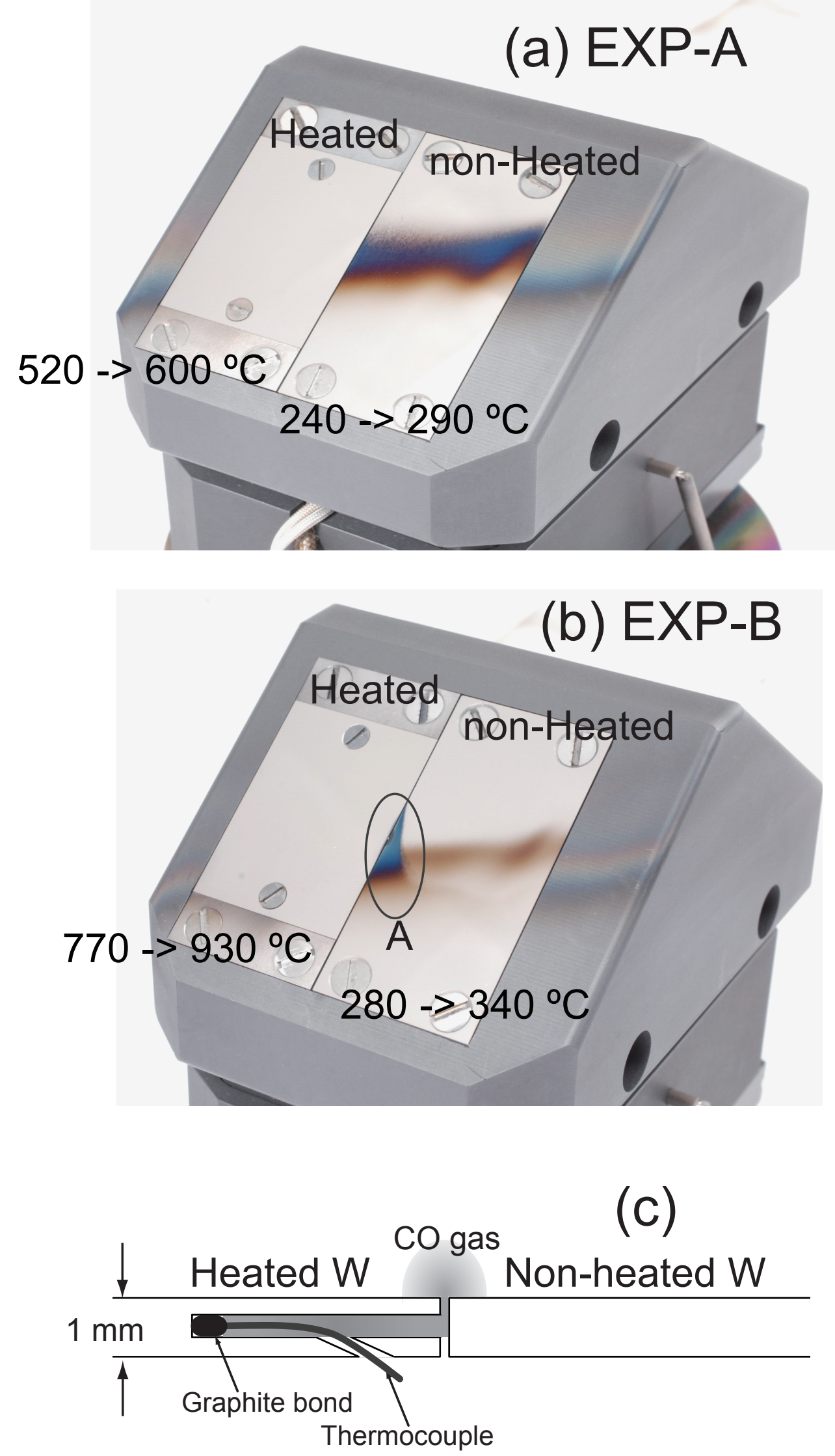

Fig. 4 


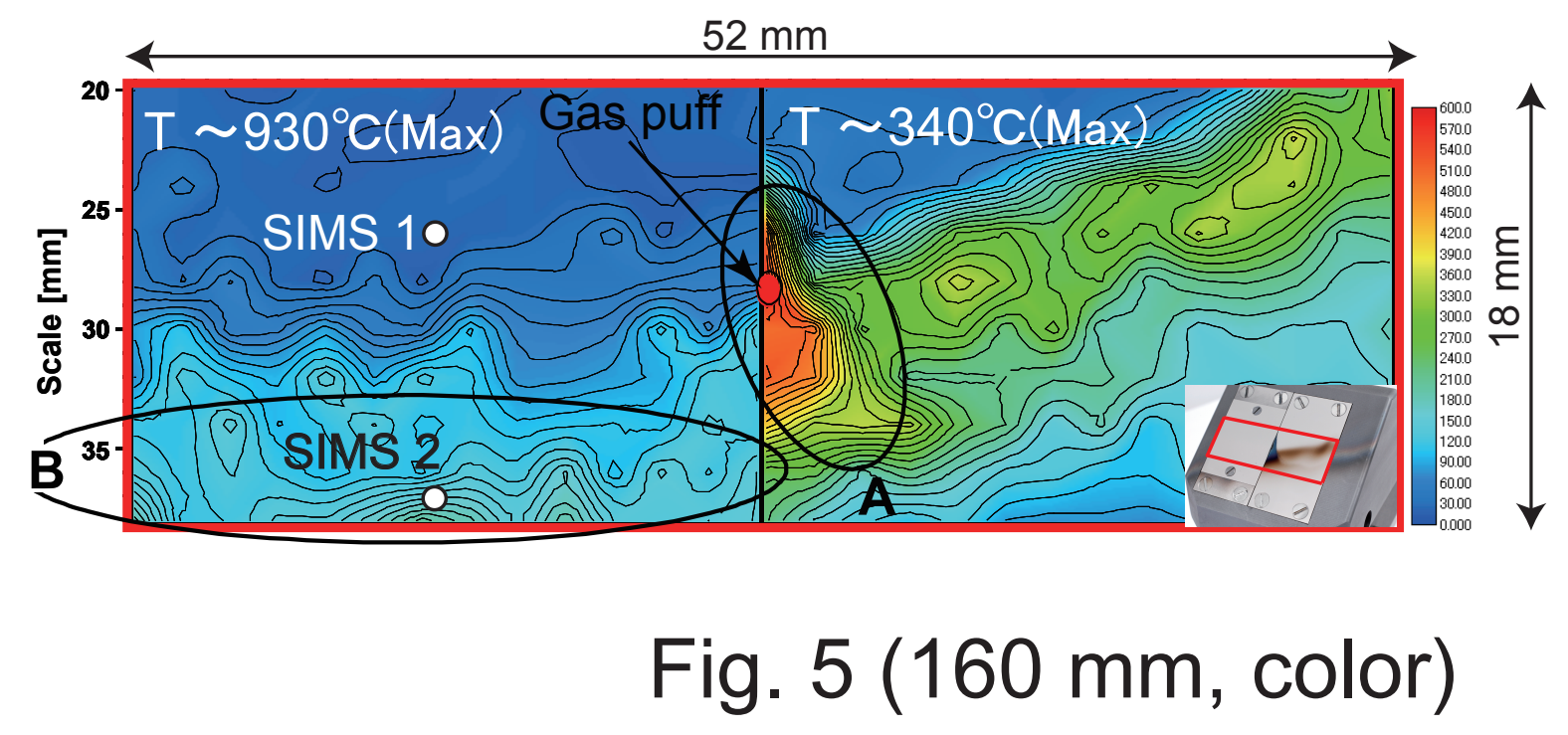



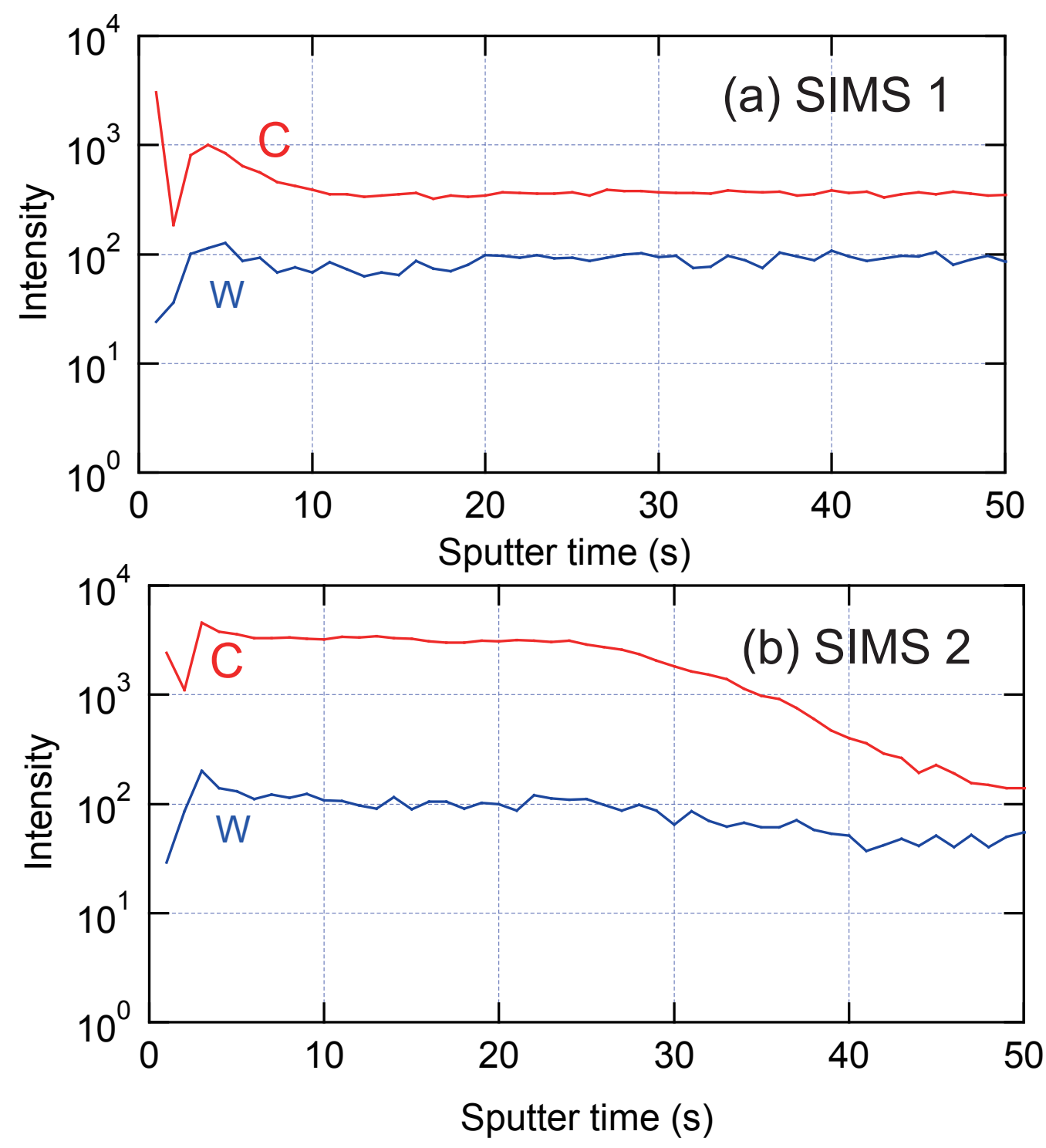

Fig. 6 